\title{
Analisis Penempatan Node Sensor Terhadap Jarak Pengambilan Data Pada Media Tanah
}

\author{
Rahman Faisal*1, Roghib Muhammad Hujja ${ }^{2}$ \\ ${ }^{1}$ Program Studi Elektronika dan Instrumentasi, FMIPA UGM, Yogyakarta \\ ${ }^{2}$ Departemen Ilmu Komputer dan Elektronika, FMIPA UGM, Yogyakarta \\ ${ }^{* 1}$ rahman.faisal@mail.ugm.ac.id, ${ }^{2}$ roghib.muh@ugm.ac.id
}

\begin{abstract}
Abstrak
Badan Nasional Penanggulangan Bencana (BNPB) menggambarkan banyaknya korban jiwa, harta dan lingkungan akibat dari tanah longsor. Teknologi jaringan sensor nirkabel dapat memperkecil terjadinya korban jiwa,harta dan lingkungan [1, 2]. Jaringan sensor nirkabel rentan terjadi gangguan terutama pada transmisi data. Transmisi data sensor wireless dapat terganggu apabila terhalang material. Lereng yang mudah longsor di Indonesia sebagian besar terdiri dari material tanah [3]. Tanah merupakan salah satu material yang dapat mengganggu transmisi data sensor wireless dan dipengaruhi aspek seperti suhu, cuaca, komposisi tanah, kelembaban tanah, dan homogenitas tanah [4, 5]. Penelitian ini berfokus menganalisa pengaruh penempatan node sensor terhadap jarak transmisi data pada material tanah berbasis WiFi. Hasil analisa penempatan node sensor yang ditanam di dalam tanah menghasilkan persentase rata-rata pelemahan kekuatan sinyal setiap bertambah kedalaman $5 \mathrm{~cm}$ pada material tanah adalah $4,90 \%$.
\end{abstract}

Kata kunci-transmisi data, soil, node sensor

\begin{abstract}
Badan Nasional Penanggulangan Bencana (BNPB) describes the number of casualties, property and environment resulting from landslides. Wireless sensor network technology can minimize the loss of life, property and environment [1, 2]. Wireless sensor networks are prone to interference, especially in data transmission. Transmission of wireless sensor data can be disrupted if material is blocked. Slides that are easily landslide in Indonesia consist mainly of soil material [3]. Soil is one material that can interfere with wireless sensor data transmission and is influenced by aspects such as temperature, weather, soil composition, soil moisture, and soil homogeneity [4, 5]. This study focuses on analyzing the effect of sensor node placement on data transmission distance on WiFi-based soil material. The results of the analysis of the placement of sensor nodes planted in the ground resulted in an average percentage attenuation of signal strength every $5 \mathrm{~cm}$ depth increase in soil material was $4.90 \%$.
\end{abstract}

Keyword - data transmission, soil, Sensor node 


\section{PENDAHULUAN}

Tanah longsor digolongkan ke dalam bencana alam yang berbahaya dan sering terjadi di Indonesia. Data dan Informasi Bencana Alam yang dikeluarkan Badan Nasional Penanggulangan Bencana menunjukkan terdapat 211 orang korban jiwa, 70 orang menghilang, 834 orang terluka dan 124.485 orang mengungsi dalam periode 1 Januari 2017 - 22 Agustus 2017. Peristiwa tanah longsor tidak mungkin dihindari, tetapi yang dapat dilakukan adalah memperkecil terjadinya korban jiwa, harta dan lingkungan dengan melakukan deteksi dini terjadinya tanah longsor tersebut menggunakan teknologi berbasis sensor. Teknologi Wireless Sensor Network (WSN) merupakan salah satu alternatif dalam pendeteksi dan peringatan dini tanah longsor tersebut [2]. Tanah longsor merupakan perpindahan material pembentuk lereng berupa pasir, Tanah, batuan, Bahan rombakan atau material campuran lainnya yang bergerak menuju bawah atau keluar lereng. Semua material pembentuk tanah longsor, tanah merupakan material pembentuk lereng yang banyak terdapat di Indonesia $[1,2]$.

WSN dapat digunakan untuk pengiriman data dan membangun sistem monitoring baik indoor maupun outdoor $[3,6]$. WSN memiliki banyak kelebihan seperti, mudah dikembangkan, jarak jangkauan yang luas dan lebih tahan terhadap gangguan luar. WSN dibutuhkan node sensor untuk menangkap gejala atau fenomena yang terjadinya pada pembacaan data sensor dan sink sebagai penghubung node sensor dan user. Teknologi wireless agar mendapatkan konektivitas yang baik diperlukan penempatan receiver maupun transmiter yang tepat untuk transmisi data $[7,8]$. Penempatan node sensor sebagai receiver sangat berhubungan dengan kuat lemahnya sinyal WiFi dalam transmisi data, sehingga menjadi salah satu faktor yang mempengaruhi jarak transmisi data [7, 9]. Penempatan node sensor rentan terjadinya gangguan yang mempengaruhi jarak transmisi data berbasis nirkabel. Lereng yang mudah longsor di Indonesia sebagian besar terdiri dari material tanah [3]. Tanah merupakan salah satu material yang dapat mengganggu transmisi data sensor wireless yang disebabkan aspek seperti suhu, cuaca, komposisi tanah, kelembaban tanah dan homogenitas tanah [4, 5]. Penempatan node sensor pada material tanah akan menyebabkan sinyal saat transmisi data dipantulkan, disebarkan atau terdifraksi yang disebabkan gangguan yang disebabkan aspek pada material tanah [10]. Oleh sebab itu, penelitian ini penelitian ini berfokus menganalisa pengaruh penempatan node sensor terhadap jarak transmisi data pada material tanah berbasis WiFi.

\section{METODE PENELITIAN}

\subsection{Analisa permasalahan}

Badan Nasional Penanggulangan Bencana (BNPB) menggambarkan banyaknya terdapat korban jiwa, harta dan lingkungan akibat tanah longsor. Teknologi jaringan sensor nirkabel atau Wireless sensor Networks (WSN) dapat memperkecil terjadinya korban jiwa, harta dan lingkungan $[1,2]$. WSN dibutuhkan node sensor untuk menangkap gejala atau fenomena yang terjadinya pada pembacaan data sensor dan sink sebagai penghubung node sensor dan user. Teknologi wireless agar mendapatkan konektivitas yang baik diperlukan penempatan receiver maupun transmiter yang tepat untuk transmisi data [7,8]. Penempatan node sensor sebagai receiver rentan terjadinya gangguan yang mempengaruhi jarak transmisi data berbasis nirkabel. Lereng yang mudah longsor di Indonesia sebagian besar terdiri dari material tanah [3]. Tanah merupakan salah satu material yang dapat mengganggu transmisi data sensor wireless yang disebabkan aspek seperti suhu, cuaca, komposisi tanah, kelembaban tanah dan homogenitas tanah [4, 5]. Penempatan node sensor pada material tanah akan menyebabkan sinyal saat transmisi data dipantulkan, disebarkan atau terdifraksi yang disebabkan gangguan yang disebabkan aspek pada material tanah [10]. Pengujian pada material tanah dilakukan dengan menempatkan node sensor pada kedalaman $10 \mathrm{~cm}, 15 \mathrm{~cm}$ dan $20 \mathrm{~cm}$ dari permukaan tanah. Sehingga, penelitian ini dapat mengenalisa pengaruh penempatan node sensor terhadap jarak transmisi data berbasis WiFi. Hasil dari penelitian ini akan menghasilkan pengaruh penempatan

IJEIS Vol. 9, No. 1, April 2019: 55 - 64 
node sensor terhadap jarak transmisi data pada material tanah dan menganalisis pelemahan kekuatan sinyal penempatan node sensor setiap penambahan kedalaman material tanah.

\subsection{Deskripsi Sistem}

Deskripsi sistem akan terlihat pada Diagram blok rancangan sistem keseluruhan. Diagram blok rancangan sistem keseluruhan dapat terlihat pada Gambar 1.

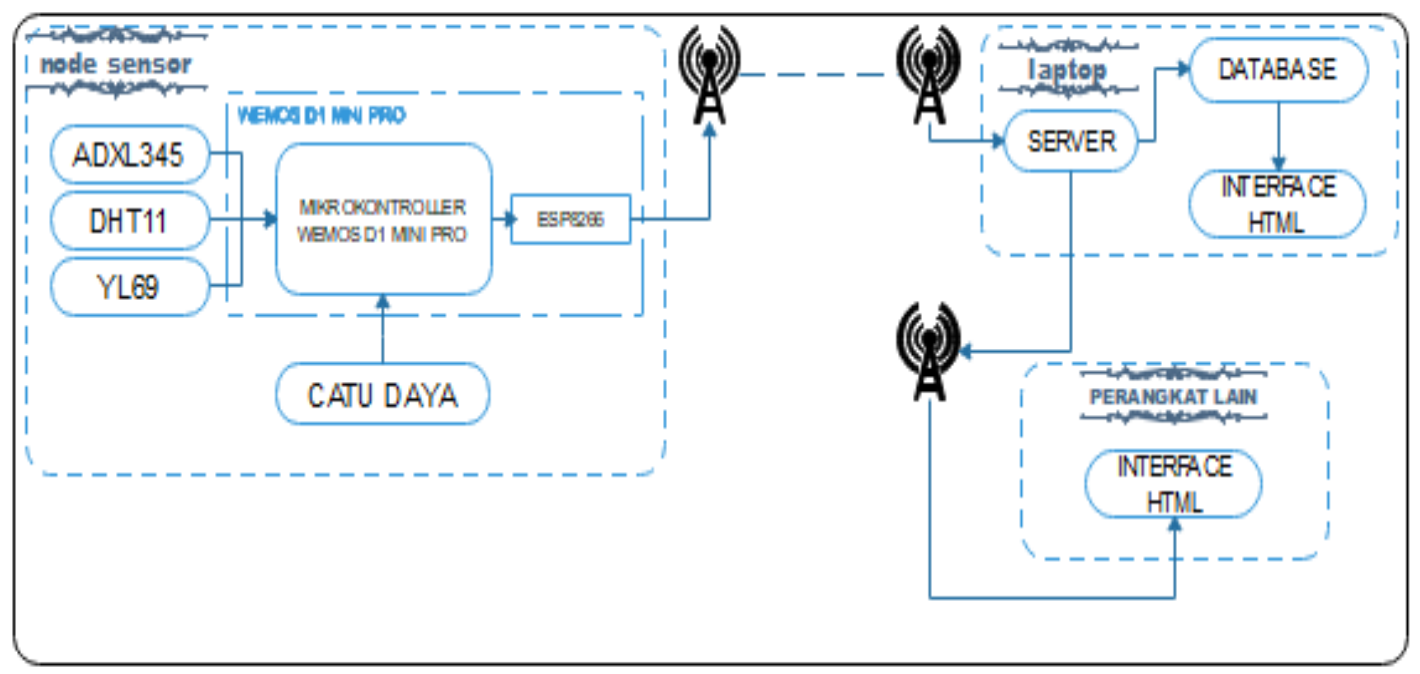

Gambar 1 Diagram Blok rancangan sistem keseluruhan

Gambar 1 merupakan Diagram blok sistem rancangan sistem keseluruhan yang terdiri dari node sensor, laptop dan perangkat lain. Node sensor digunakan untuk mengakuisisi data yang dibaca sensor, sehingga diteruskan ke server melalui chip ESP8266EX yang digunakan untuk transmisi data secara nirkabel. Laptop digunakan sebagai server transmiter yang terdiri dari database dan interface html. Perangkat lain digunakan untuk interface tampilan yang dipancarkan oleh server pada laptop.

\subsection{Rancangan Sistem}

Rancangan sistem bertujuan memberikan gambaran umum sebuah sistem yang akan digunakan untuk penelitian. Perancangan terbagi menjadi 2 bagian yang meliputi perancangan perangkat keras dan perancangan perangkat lunak.

\subsubsection{Perancangan perangkat keras}

Perancangan perangkat keras bermaksud memberikan gambaran umum perangkat keras yang digunakan pada sistem. Perancangan perangkat keras akan terlihat pada Gambar 2.

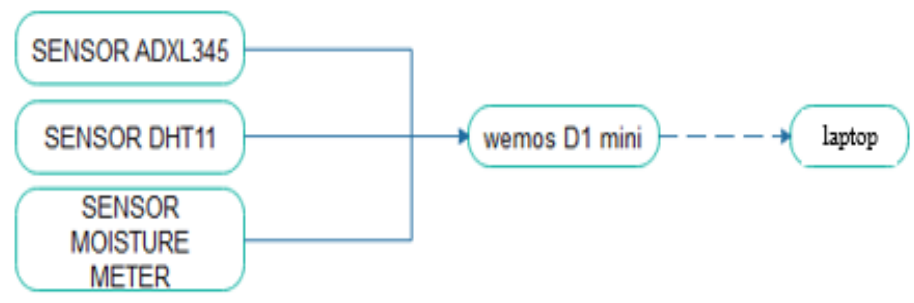

Gambar 2 rancangan perangkat keras node sensor

Gambar 2 menjelaskan rancangan perangkat keras node sensor sebuah sistem. Rancangan ini dibangun dengan input yang berasal dari sensor ADXL345, sensor DHT11 dan 
sensor Moisture meter. Wemos D1 mini pro digunakan untuk mikrokontroller yang akan memproses masukan supaya data dikirim ke keluaran yang ditampilkan dan disimpan di dalam laptop. Chip ESP8266EX merupakan chip WiFI yang digunakan untuk pengiriman data yang diproses dalam mikrokontroller menuju output berbasis nirkabel. Rancangan ini berjalan ketika dihubungkan dengan catu daya berupa baterai atau Powerbank.

\subsubsection{Perancangan perangkat lunak}

Perancangan perangkat lunak bertujuan untuk membangun rancangan hingga membentuk perangkat lunak. Perancangan perangkat lunak terbagi atas perancangan node sensor, perancangan pengiriman ke server, database dan interface.

a. Perancangan node sensor

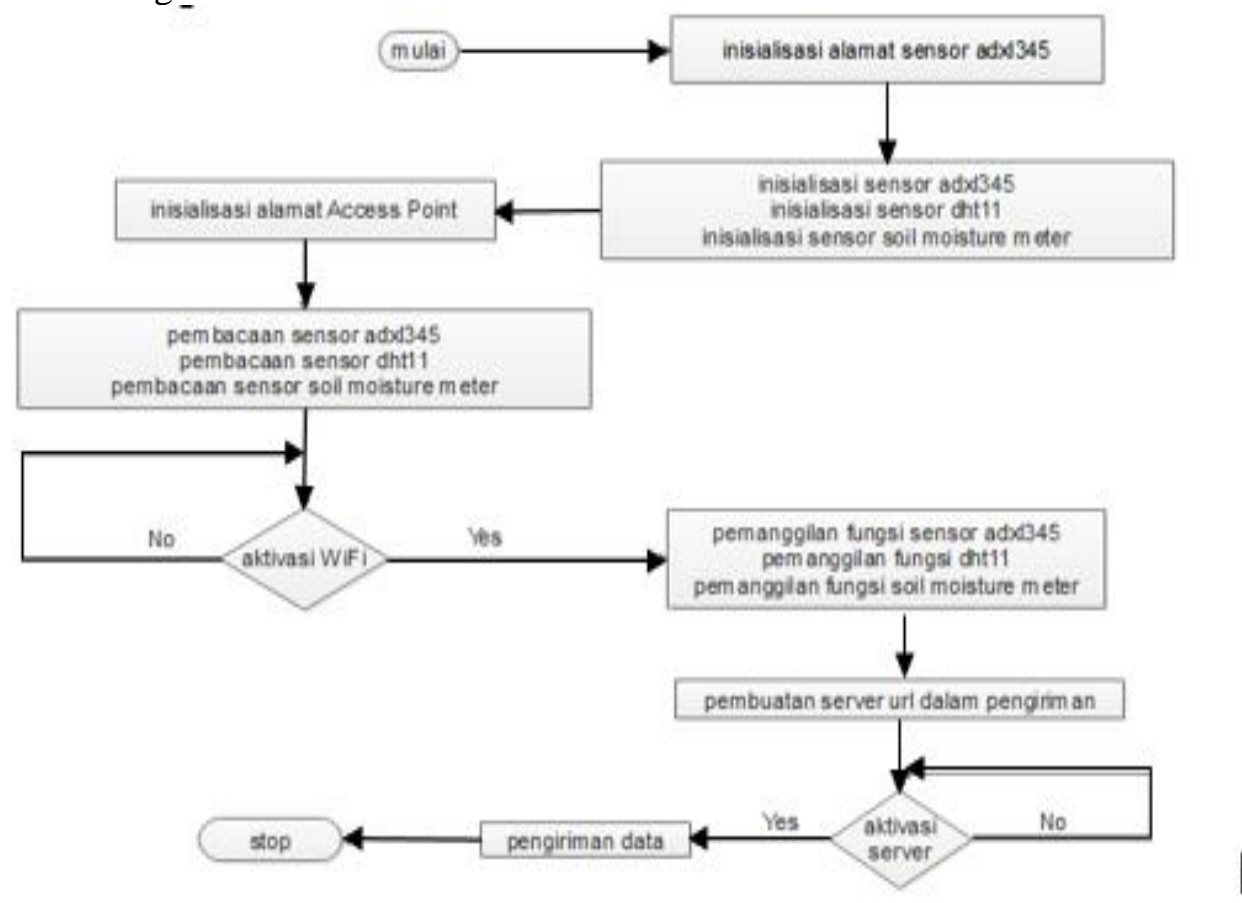

Gambar 3 flowchart node sensor

Gambar 3 merupakan flowchart node sensor sistem yang digunakan pada penelitian ini. Node sensor berjalan pertama kali dengan menginisialisasikan alamat sensor, sensor dan alamat Access Point. Ketika sensor sudah membaca data maka akses WiFi harus di hidupkan agar data hasil sensor dapat dikirim ke server. Pengolahan node sensor ini menggunakan arduino IDE sehingga sensor bisa membaca data dan dikonversikan menjadi data digital pada mikrokontroler.

b. Perancangan pengiriman data sensor ke server

Perancangan pengiriman data sensor menuju server merupakan bagian dari perancangan perangkat lunak yang berfungsi sebagai transmisi data. Cara kerja transmisi data dapat terlihat pada Gambar 4.

IJEIS Vol. 9, No. 1, April 2019: 55-64 


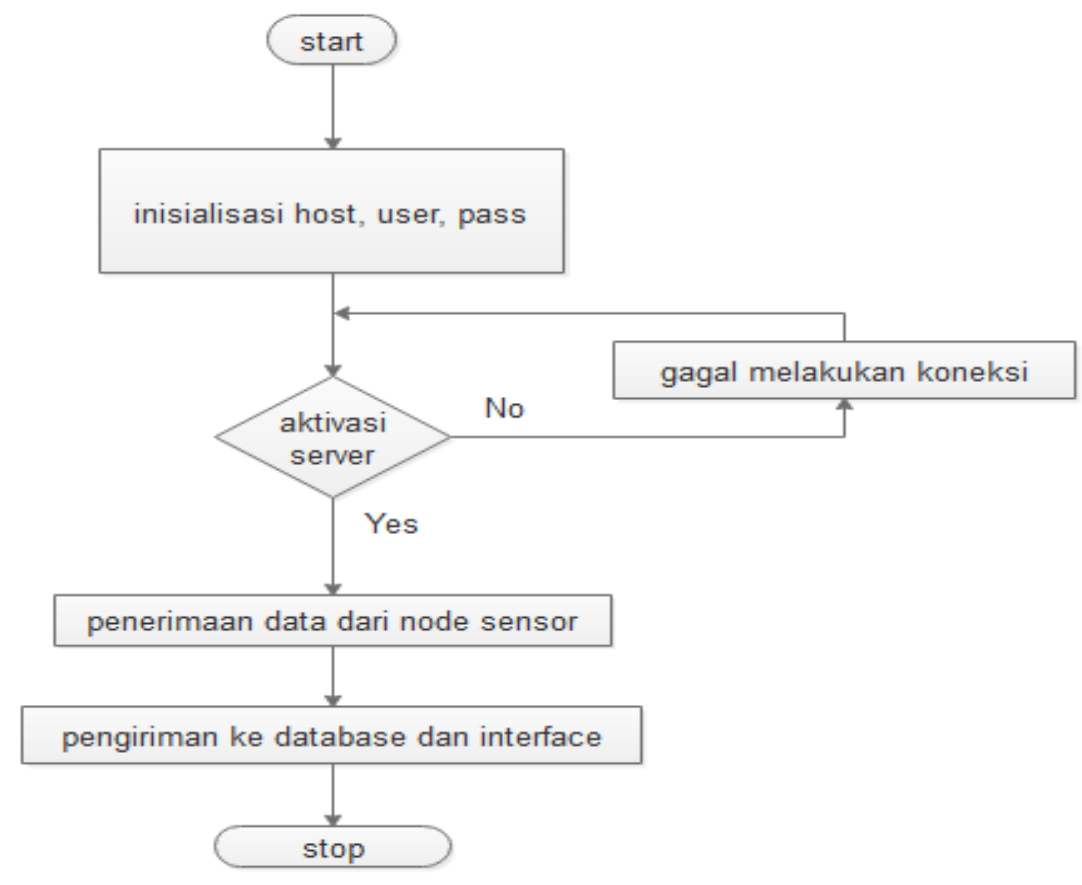

Gambar 4. Flowchart transmisi data

Transmisi data dimulai dengan menginisialisasi Host, user dan pass setelah terinisialisasi maka dilanjutkan dengan menghidupkan server agar dapat melakukan koneksi dengan server. Ketika transmisi data telah dilakukan dan server sudah dihidupkan maka dapat melakukan pengiriman ke database dan diolah pada interface.

\section{c. Perancangan database}

Perancangan database merupakan bagian perancangan perangkat lunak yang digunakan untuk penyimpanan pembacaan data sehingga tersimpan walaupun data baru muncul. Flowchart perancangan database dapat terlihat pada Gambar 5.

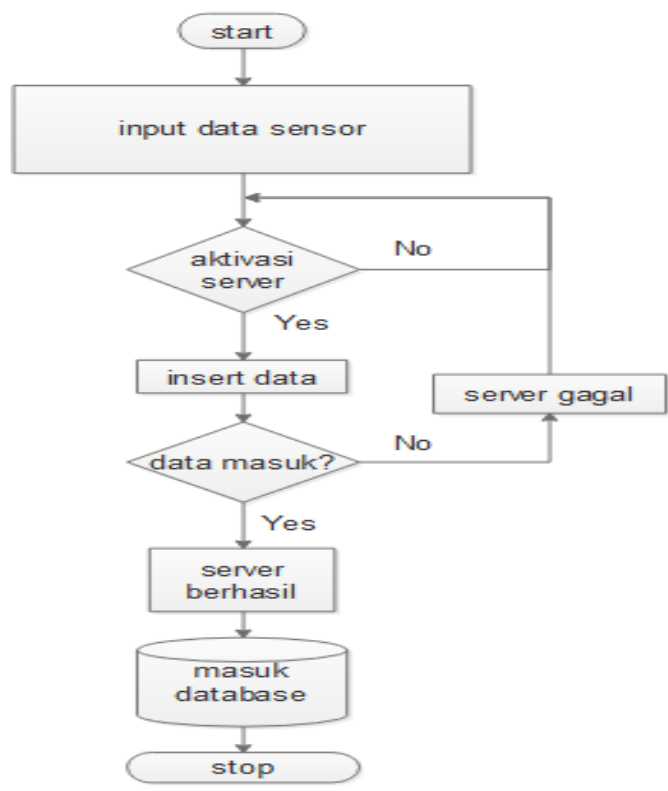

Gambar 5 Flowchart perancangan database 
Gambar 5 merupakan flowchart perancangan database yang digunakan untuk memasukan data sensor yang disimpan di dalam database. data dari node sensor akan dilalui melalui server, ketika server belum aktif maka data tidak bisa tersimpan di dalam database. ketika server sudah aktif, maka data akan masuk ke dalam database dan data dari node sensor sudah tersimpan di dalam database.

d. Perancangan interface

Perancangan interface berguna untuk tampilan hasil Monitoring pembacaan data dari sensor. Perancangan interface dapat terlihat pada Gambar 6.

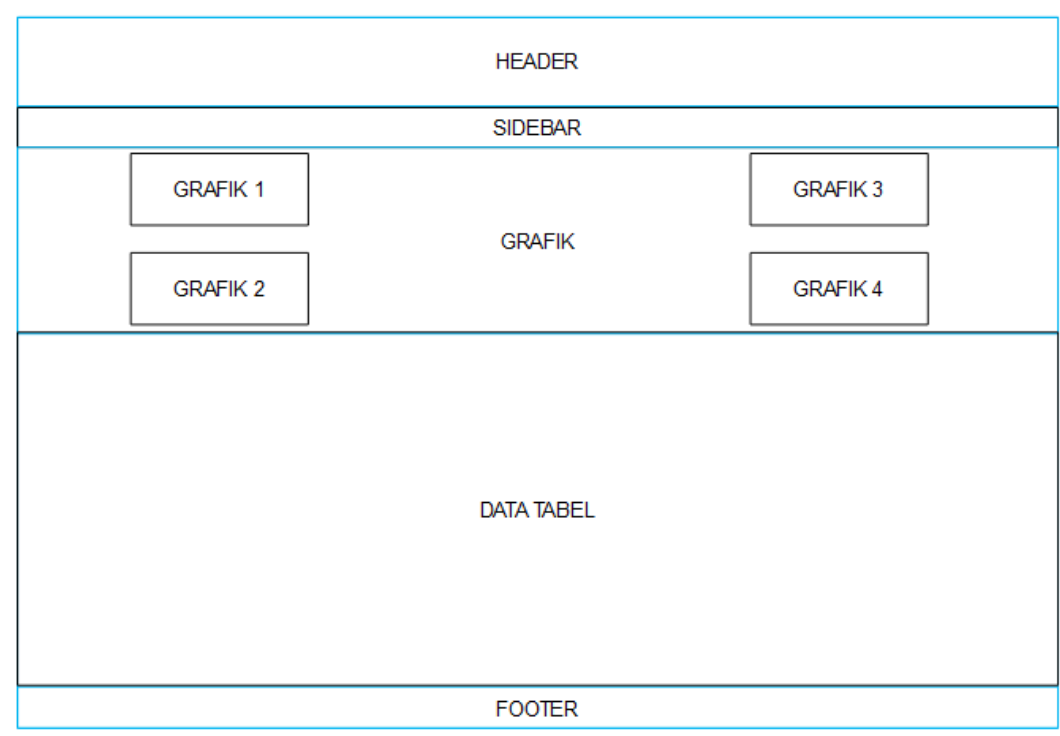

Gambar 6 Tampilan interface html

Gambar 6 merupakan tampilan interface html yang akan dibentuk sebagai tampilan Monitoring dari data yang tersimpan dalam database. Interface diatas terdiri dari header, sidebar, grafik, data tabel dan footer. Data tabel terdiri dari 100 data terbaru yang tersimpan di dalam database, sedangkan grafik akan menampilkan grafik 10 data terbaru yang tersimpan di dalam database.

\section{HASIL DAN PEMBAHASAN}

\subsection{Hasil Percobaan pada material tanah kedalaman $10 \mathrm{~cm}$}

Percobaan ini dilakukan untuk mengetahui kekuatan sinyal yang diterima oleh laptop dari pancaran sinyal yang dikeluarkan oleh node sensor ketika penempatan node sensor ditempatkan pada material tanah dengan kedalaman $10 \mathrm{~cm}$ dari permukaan tanah. Pengukuran dilakukan dengan mengukur besarnya kekuatan sinyal yang diterima oleh laptop sebagai server dari pancaran sinyal yang telah dikeluarkan oleh node sensor. Pengukuran dilakukan dengan menjarakkan node sensor dan laptop dengan kelipatan 3 meter, tetapi ketika mendekati titik buta jarak transmisi data maka jarak akan diperkecil menjadi kelipatan 1 meter. Pengambilan data dilakukan setelah kekuatan sinyal keliatan stabil dan dengan jeda 1 menit. Hasil percobaan pada material tanah dengan kedalaman $10 \mathrm{~cm}$ dapat terlihat pada Tabel 1.

IJEIS Vol. 9, No. 1, April 2019: 55 - 64 
Tabel 1 percobaan pada material tanah kedalaman $10 \mathrm{~cm}$

\begin{tabular}{|c|c|c|c|c|c|c|}
\hline \multicolumn{2}{|c|}{ Percobaan } & \multicolumn{5}{|c|}{ percobaan di kedalaman tanah $10 \mathrm{~cm}$} \\
\hline \multicolumn{2}{|c|}{ tanggal dan waktu : } & \multicolumn{5}{|l|}{$27 / 08 / 201809.43$} \\
\hline $\begin{array}{l}\text { jarak } \\
(\mathrm{m}) \\
\end{array}$ & $\begin{array}{l}\text { signal } \\
(\mathrm{dBm}) \\
\end{array}$ & $\begin{array}{c}\text { percentase of } \\
\text { current signal }(\%)\end{array}$ & $\begin{array}{c}\text { max signal } \\
(\mathrm{dBm}) \\
\end{array}$ & $\begin{array}{c}\text { min signal } \\
(\mathrm{dBm}) \\
\end{array}$ & $\begin{array}{c}\text { average signal } \\
(\mathrm{dBm})\end{array}$ & $\begin{array}{l}\text { terkirim/tida } \\
\mathrm{k} \text { terkirim }\end{array}$ \\
\hline 0 & -65 & 36 & -65 & -40 & -63 & Terkirim \\
\hline 3 & -74 & 26 & -65 & -40 & -70 & Terkirim \\
\hline 6 & -84 & 15 & -85 & -40 & -81 & Terkirim \\
\hline 9 & -85 & 14 & -85 & -40 & -82 & Terkirim \\
\hline 10 & -87 & 12 & -87 & -40 & -84 & Terkirim \\
\hline 11 & -89 & 10 & -96 & -40 & -86 & Terkirim \\
\hline 12 & -90 & 9 & -96 & -40 & -87 & Terkirim \\
\hline 13 & -90 & 8 & -96 & -40 & -88 & Terkirim \\
\hline 14 & -90 & 7 & -96 & -40 & -90 & Terkirim \\
\hline 15 & - & - & -96 & -40 & - & $\begin{array}{c}\text { tidak } \\
\text { terkirim }\end{array}$ \\
\hline
\end{tabular}

Tabel 1 merupakan percobaan pada material tanah dengan kedalaman $10 \mathrm{~cm}$. Data dari tabel 1 memperlihatkan jarak maksimum transmisi data pada material tanah kedalaman $10 \mathrm{~cm}$ adalah 14 meter. Maksimum dan minimum kekuatan sinyal pada material tanah kedalaman 10 $\mathrm{cm}$ adalah $-65 \mathrm{dBm}$ dan $-90 \mathrm{dBm}$. Pelemahan kekuatan sinyal terbesar terlihat pada jarak 3 meter menuju 6 meter. Jarak 15 meter pada percobaan material tanah dengan kedalaman $10 \mathrm{~cm}$ tidak dapat lagi melakukan transmisi data atau pengiriman data.

\subsection{Hasil Percobaan pada material tanah kedalaman $15 \mathrm{~cm}$}

Percobaan ini dilakukan dengan menempatkan node sensor di material tanah pada kedalaman $15 \mathrm{~cm}$. Percobaan ini dilakukan pada kawasan yang sama seperti percobaan sebelumnya, tetapi penempatan node sensor yang berbeda. Hasil data percobaan pada material Tanah dengan kedalaman $15 \mathrm{~cm}$ dapat terlihat pada Tabel 2.

Tabel 2 percobaan pada material tanah kedalaman $15 \mathrm{~cm}$

\begin{tabular}{|c|c|c|c|c|c|c|}
\hline \multirow{2}{*}{\multicolumn{2}{|c|}{$\begin{array}{l}\text { Percobaan : } \\
\text { tanggal dan } \\
\text { waktu : } \\
\end{array}$}} & \multicolumn{5}{|c|}{ percobaan di kedalaman tanah $15 \mathrm{~cm}$} \\
\hline & & \multicolumn{5}{|l|}{$27 / 08 / 201810.13$} \\
\hline $\begin{array}{l}\text { jarak } \\
(\mathrm{m}) \\
\end{array}$ & $\begin{array}{r}\text { signal } \\
(\mathrm{dBm}) \\
\end{array}$ & $\begin{array}{c}\text { percentase of current } \\
\text { signal }(\%)\end{array}$ & $\begin{array}{c}\text { max signal } \\
(\mathrm{dBm})\end{array}$ & $\begin{array}{c}\text { min signal } \\
(\mathrm{dBm})\end{array}$ & $\begin{array}{l}\text { average } \\
\text { signal }\end{array}$ & $\begin{array}{c}\text { terkirim/tidak } \\
\text { terkirim }\end{array}$ \\
\hline 0 & -70 & 29 & -96 & -40 & -70 & terkirim \\
\hline 3 & -75 & 24 & -96 & -40 & -74 & terkirim \\
\hline 6 & -82 & 17 & -96 & -40 & -80 & terkirim \\
\hline 7 & -88 & 12 & -96 & -40 & -87 & terkirim \\
\hline 8 & -88 & 10 & -96 & -40 & -88 & terkirim \\
\hline 9 & -89 & 8 & -96 & -40 & -89 & terkirim \\
\hline 10 & - & - & -96 & -40 & - & tidak terkirim \\
\hline
\end{tabular}


Tabel 2 merupakan percobaan pada material tanah dengan kedalaman $15 \mathrm{~cm}$ dari permukaan tanah. Data dari tabel 2 memperlihatkan jarak maksimum transmisi data material tanah dengan kedalaman $15 \mathrm{~cm}$ adalah 9 meter. Maksimum dan minimum kekuatan sinyal pada material tanah dengan kedalaman $15 \mathrm{~cm}$ adalah $-70 \mathrm{dBm}$ dan $-89 \mathrm{dBm}$. Pelemahan kekuatan sinyal terbesar terlihat pada jarak 3 meter menuju 6 meter. Jarak 10 meter merupakan jarak yang tidak bisa lagi melakukan transmisi data atau pengiriman data.

\subsection{Hasil percobaan pada material tanah dengan kedalaman $20 \mathrm{~cm}$}

Percobaan ini dilakukan pada kawasan dan kondisi yang sama seperti percobaan sebelumnya, tetapi penempatan node sensor yang berbeda. Penempatan node sensor pada material tanah dengan kedalaman $20 \mathrm{~cm}$. Hasil data percobaan pada material dengan kedalaman $20 \mathrm{~cm}$ dapat terlihat pada Tabel 3 .

Tabel 3. Percobaan pada material tanah kedalaman $20 \mathrm{~cm}$

\begin{tabular}{|c|c|c|c|c|c|c|}
\hline \multicolumn{6}{|c|}{ Percobaan : } & \multicolumn{5}{l}{ percobaan di kedalaman tanah $20 \mathrm{~cm}$} \\
\hline $\begin{array}{c}\text { tanggal dan } \\
\text { waktu : }\end{array}$ & \multicolumn{5}{l}{ 27/08/2018 10.42 } \\
\hline $\begin{array}{c}\text { jarak } \\
(\mathrm{m})\end{array}$ & $\begin{array}{c}\text { signal } \\
(\mathrm{dBm})\end{array}$ & $\begin{array}{c}\text { percentase of } \\
\text { current signal } \\
(\%)\end{array}$ & $\begin{array}{c}\text { min } \\
\text { signal } \\
(\mathrm{dBm})\end{array}$ & $\begin{array}{c}\text { max } \\
\text { signal } \\
(\mathrm{dBm})\end{array}$ & $\begin{array}{c}\text { average } \\
\text { signal } \\
(\mathrm{dBm})\end{array}$ & $\begin{array}{c}\text { terkirim/tidak } \\
\text { terkirim }\end{array}$ \\
\hline \hline 0 & -78 & 22 & -96 & -40 & -77 & Terkirim \\
\hline 3 & -79 & 20 & -96 & -40 & -78 & Terkirim \\
\hline 4 & -83 & 16 & -96 & -40 & -80 & Terkirim \\
\hline 5 & -87 & 12 & -96 & -40 & -84 & Terkirim \\
\hline 6 & -87 & 10 & -96 & -40 & -86 & Terkirim \\
\hline 7 & -93 & 7 & -96 & -40 & -90 & Terkirim \\
\hline 8 & - & - & -96 & -40 & - & tidak terkirim \\
\hline
\end{tabular}

Tabel 3 merupakan data hasil percobaan pada material tanah dengan kedalaman $20 \mathrm{~cm}$. data dari tabel 3 memperlihatkan jarak maksimum transmisi data material tanah dengan kedalaman $20 \mathrm{~cm}$ adalah 7 meter. Kekuatan sinyal maksimum dan minimum pada material tanah dengan kedalaman $20 \mathrm{~cm}$ adalah $-78 \mathrm{dBm}$ dan $-93 \mathrm{dBm}$. Pelemahan kekuatan sinyal terbesar terjadi pada jarak 3 meter menuju 4 meter. Jarak 8 meter merupakan jarak yang tidak bisa lagi melakukan transmisi data atau pengiriman data

\subsection{Perbandingan pengujian pada material tanah}

Perbandingan data pengujian pada material tanah sangat diperlukan untuk mengetahui persentase perubahan kekuatan sinyal setiap penempatan node sensor. Perbandingan ini menggambarkan efektivitas pengaruh penempatan node sensor berdasarkan jarak transmisi data pada material tanah berbasis WiFi. Perbandingan pada material tanah dapat terlihat pada Gambar 8 .

IJEIS Vol. 9, No. 1, April 2019: 55-64 


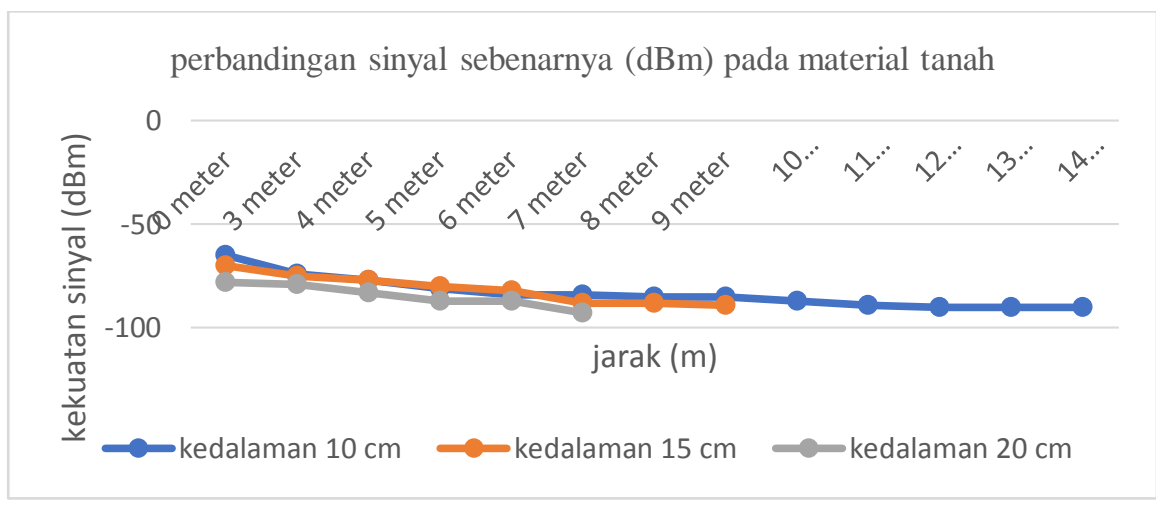

Gambar 8 grafik pengujian pada material tanah

Gambar 8 merupakan grafik pengujian pada material tanah dengan kedalaman $10 \mathrm{~cm}$, $15 \mathrm{~cm}$ dan $20 \mathrm{~cm}$. Grafik diatas memperlihatkan terjadi selisih jarak transmisi data antara kedalaman $10 \mathrm{~cm}, 15 \mathrm{~cm}$ dan $20 \mathrm{~cm}$. Selisih jarak antara kedalaman $10 \mathrm{~cm}$ dan kedalaman 15 $\mathrm{cm}$ adalah 5 meter. Selisih jarak antara kedalaman $15 \mathrm{~cm}$ dan kedalaman $20 \mathrm{~cm}$ adalah 2 meter, selisih jarak antara kedalaman $10 \mathrm{~cm}$ dan kedalaman $20 \mathrm{~cm}$ adalah 7 meter. Maka, rata-rata selisih jarak transmisi data dengan penambahan kedalaman $5 \mathrm{~cm}$ pada material tanah adalah 3,5 meter. Pelemahan kekuatan sinyal pengujian pada material tanah terlihat pada Tabel 4.

Tabel 4 perbandingan pengujian pada material tanah

\begin{tabular}{|c|c|c|c|c|c|c|}
\hline $\begin{array}{c}\text { jarak } \\
(\mathrm{m})\end{array}$ & $\begin{array}{l}\text { kedalaman } \\
10 \mathrm{~cm} \\
(\mathrm{dBm})\end{array}$ & $\begin{array}{c}\text { kedalaman } \\
15 \mathrm{~cm} \\
(\mathrm{dBm})\end{array}$ & $\begin{array}{l}\text { kedalaman } \\
20 \mathrm{~cm} \\
(\mathrm{dBm})\end{array}$ & $\begin{array}{l}\text { pelemahan } \\
\text { sinyal } 10-15 \\
\text { cm }(\%)\end{array}$ & $\begin{array}{l}\text { pelemahan } \\
\text { sinyal } 15-20 \\
\text { cm }(\%)\end{array}$ & $\begin{array}{c}\text { pelemahan } \\
\text { sinyal } 10-20 \\
\text { cm }(\%)\end{array}$ \\
\hline 0 & $-65,0$ & $-70,0$ & $-78,0$ & $7,69 \%$ & $11,4 \%$ & $20,0 \%$ \\
\hline 3 & $-74,0$ & $-75,0$ & $-79,0$ & $1,35 \%$ & $5,33 \%$ & $6,76 \%$ \\
\hline 4 & $-77,0$ & $-77,0$ & $-83,0$ & $0,00 \%$ & $7,79 \%$ & $7,79 \%$ \\
\hline 5 & $-81,0$ & $-80,0$ & $-87,0$ & $-1,23 \%$ & $8,75 \%$ & $7,41 \%$ \\
\hline 6 & $-84,0$ & $-82,0$ & $-87,0$ & $-2,38 \%$ & $6,10 \%$ & $3,57 \%$ \\
\hline 7 & $-84,0$ & $-88,0$ & $-93,0$ & $4,76 \%$ & $5,68 \%$ & $10,7 \%$ \\
\hline 8 & $-85,0$ & $-88,0$ & & $3,53 \%$ & & \\
\hline 9 & $-85,0$ & $-89,0$ & & $4,71 \%$ & & \\
\hline 10 & $-87,0$ & & & & & \\
\hline 11 & $-89,0$ & & & & & \\
\hline 12 & $-90,0$ & & & & & \\
\hline 13 & $-90,0$ & & & & & \\
\hline 14 & $-90,0$ & & & & & \\
\hline \multicolumn{4}{|c|}{ rata-rata pelemahan sinyal } & $2,30 \%$ & $7,51 \%$ & $9,37 \%$ \\
\hline \multicolumn{4}{|c|}{ maksimal pelemahan sinyal } & $7,67 \%$ & $11,4 \%$ & $20,0 \%$ \\
\hline \multicolumn{4}{|c|}{ minimal pelemahan sinyal } & $-2,38 \%$ & $5,33 \%$ & $3,57 \%$ \\
\hline \multicolumn{4}{|c|}{ penurunan jarak transmisi data } & $35,7 \%$ & $22,2 \%$ & $50,0 \%$ \\
\hline
\end{tabular}


Tabel 4 merupakan perbandingan pelemahan kekuatan sinyal pada pengujian material tanah. data yang ditampilkan pada tabel 4 memperlihatkan bahwa persentase rata-rata pelemahan kekuatan sinyal pada kedalaman $10-15 \mathrm{~cm}$ adalah 2,30\%. Persentase rata-rata pelemahan kekuatan sinyal pada kedalaman $15-20 \mathrm{~cm}$ adalah $7,51 \%$. Persentase rata-rata pelemahan kekuatan sinyal setiap bertambah kedalaman $5 \mathrm{~cm}$ adalah $4,90 \%$, Sedangkan persentase rata-rata pelemahan kekuatan sinyal pada kedalaman $10-20 \mathrm{~cm}$ adalah $9,37 \%$.

\section{KESIMPULAN}

Penelitian yang dilakukan di lingkungan embung dengan melakukan pengujian penempatan node sensor tertanam pada material tanah kedalaman $10 \mathrm{~cm}, 15 \mathrm{~cm}$ dan $20 \mathrm{~cm}$. Penelitian ini menemukan bahwa Kinerja penempatan node sensor yang tertanam pada material tanah sangat mempengaruhi jarak pengambilan data berbasis nirkabel. Hasil penelitian ini memperlihatkan bahwa setiap bertambahnya kedalaman penempatan node sensor pada tanah sebesar $5 \mathrm{~cm}$ akan memperkecil jarak pengambilan data sebesar $28.95 \%$. Material tanah yang digunakan berupa lumpur pada embung tersebut.

\section{SARAN}

Pengembangan lebih lanjut disarankan untuk penempatan node sensor lebih bervariasi dan material tanah yang lebih bermacam agar menghasilkan data yang lebih presisi dan akurat. Deskripsikan interferensi dan gangguan pada material tanah sehingga dapat menghasilkan data yang lebih akurat berdasarkan pengukuran matematis. Penggunaan antena dan daya yang lebih besar untuk memperkuat kekuatan sinyal berbasis nirkabel.

\section{DAFTAR PUSTAKA}

[1] T. Hidayat, "Sistem Pendeteksi Dini Longsor Menggunakan Teknologi Wireless Sensor Network (WSN)," Jurnal Teknik Elektro ITP, vol. 6, no. 1, hlm. 87-92, Feb 2017.

[2] W. I. Lesmana dan M. C. Wibowo, "Penerapan Wireless Sensor Network (Wsn) Dengan Topologi Tree Pada Pemantauan Tanah Longsor," vol. 13, no. 1, hlm. 6, 2015.

[3] S. Adinandra, "Wireless Sensor Network Untuk Pengumpulan Data Bergerak Pada Sistem Informasi Medis," hlm. 8, 2013.

[4] S. Barai, D. Biswas, dan B. Sau, "Estimate distance measurement using NodeMCU ESP8266 based on RSSI technique," 2017, hlm. 170-173.

[5] A. R. Silva dan M. C. Vuran, "Communication with Aboveground Devices in Wireless Underground Sensor Networks: An Empirical Study," dalam 2010 IEEE International Conference on Communications, Cape Town, South Africa, 2010, hlm. 1-6.

[6] I. Santosa, "Karakteristik Propagasi di Outdoor berdasarkan Analisis RSSI pada Jaringan Sensor Nirkabel," vol. 1, no. 3, hlm. 10, 2015.

[7] W. F. Dewantara, S. R. Akbar, dan R. Primananda, "Implementasi Light Painting Photography Dalam Analisis Cakupan Jaringan Wireless LAN Menggunakan Perangkat Berbasis Wemos D1," hlm. 11.

[8] M. Subchan dan A. Goeritno, "Kinerja Router pada Jaringan Nirkabel untuk Penentuan Jarak Jangkauan Sinyal," hlm. 12, 2017.

[9] P. W. Ginta, "Analisa dan Implementasi Wireless Extension Point dengan SSID (Service Set Identifier)," vol. 13, no. 1, hlm. 11, 2017.

[10] "Experiment measurements of RSSI for wireless underground sensor network in soil." [Daring]. Tersedia pada: https://www.researchgate.net/publication/325626609_Experiment_measurements_of_R SSI_for_wireless_underground_sensor_network_in_soil. [Diakses: 31-Okt-2018]. 